\title{
Tod und Jenseits im alten Israel und in seiner Umwelt
}

Theologische, religionsgeschichtliche, archäologische und ikonographische Aspekte Hrsg. v. Angelika Berlejung u. Bernd Janowski in Zus.-Arb. m. Jan Dietrich u. Annette Krüger

Tod und Jenseits im alten Israel und in seiner Umwelt Herausgegeben von
ANGELIKA BERLEJUNG ANGELIKA BERLEJUNG

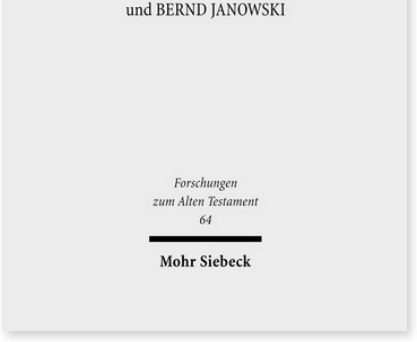

2009. XII, 723 Seiten. FAT 64

ISBN 978-3-16-151105-9

DOI 10.1628/978-3-16-151105-9

eBook PDF $149,00 €$

ISBN 978-3-16-149776-6

Leinen $149,00 €$
International renommierte Forscher untersuchen das Thema »Tod und Jenseits« als ein interdisziplinäres und interkulturelles Forschungsfeld, in dem die unterschiedlichsten Aspekte präsentiert und miteinander in Beziehung gesetzt werden. Sie arbeiten mit verschiedenen methodischen Ansätzen der Exegese, der Religionsgeschichte, der Ikonographie, der Altorientalistik bzw. Ägyptologie, der Archäologie und der gender-orientierten Forschung auf der Basis neuester Forschungen und Funde.

Im Zentrum stehen die unterschiedlichen Entwicklungen in Bezug auf Todesvorstellungen und Grabsitten, die im 3.-1. Jt. v. Chr. Ägypten, Mesopotamien, Syrien und die Levante prägten. In diesen kulturgeschichtlichen Kontext können die verschiedenen literarischen Traditionen des Alten Testaments differenziert eingeordnet werden, da sie sich an verschiedenen zeitgenössischen Diskursen um Tod und Jenseits beteiligten, um erst seit dem 7., 6. oder 5. Jh. v. Chr. den Todesbereich in das Gesamtprofil des entstehenden monotheistischen Gottesbilds zu integrieren. Doch zeigen die Arbeiten zu den alttestamentlichen und frühjüdischen Texten auch, wie vielfältig die Vorstellungen hinsichtlich der postmortalen Existenz am Ende des 1. Jt. v. Chr. und am Anfang des 1. Jt. n. Chr. waren. Regionale Aspekte und konkurrierende theologische Tendenzen sorgten dafür, dass keine auch nur annähernd konsistente »Auferstehungslehre« entstand. Es wird vielmehr deutlich, dass die antike Welt vom 3. Jt. v. Chr. bis zum Frühjudentum keine Notwendigkeit darin sah, ein geschlossenes System an Todes-, Unterwelts-, Jenseits- und Auferstehungsvorstellungen zu entwerfen.

Inhaltsübersicht

Angelika Berlejung / Bernd Janowski: Einleitung Der Mensch und sein Tod - übergreifende Aspekte

Johannes Schnocks: Vergänglichkeit und Gottesferne - Christian Frevel: Dann wär' ich nicht mehr da. Der Todeswunsch ljobs als Element der Klagerhetorik - Rüdiger Lux: Tod und Gerechtigkeit im Buch Kohelet - Stefanie Ulrike Gulde: Der Tod als Figur im Alten Testament. Ein alttestamentlicher Motivkomplex und seine Wurzeln - Irmtraud Fischer: Ist der Tod nicht für alle gleich? Sterben und Tod aus Genderperspektive

Der gute und der schlechte Tod - zur Bewertung des Todes

Ute Neumann-Gorsolke: »Alt und lebenssatt ...«. Der Tod zur rechten Zeit

Annette Krüger: Auf dem Weg »zu den Vätern« - Traditionsgeschichtliche Beobachtungen zu einer Sterbeformel - Martin Leuenberger: Das Problem des vorzeitigen Todes in der israelitischen Religions- und Theologiegeschichte - Jan Dietrich: Der Tod von eigener Hand im Alten Testament und Alten Orient. Eskapistische, aggressive und oblative Selbsttötungen - Angelika Berlejung: Bilder von Toten - Bilder für die Lebenden. Sterben und Tod in der Ikonographie des Alten Orients, Ägyptens und Palästinas

Bestattungs- und Trauerriten - zur rituellen Bewältigung des Todes I

Jens Kamlah: Grab und Begräbnis in Israel/Juda. Materielle Befunde, Jenseitsvorstellungen und die Frage des Totenkultes Silvia Schroer: Trauerriten und Totenklage im Alten Israel. Frauenmacht und Machtkonflikte - Herbert Niehr: Die Königsbestattung im Palast von Ugarit. Ein Rekonstruktionsversuch der Übergangsriten aufgrund schriftlicher und archäologischer Daten - Reinhard Achenbach: Verunreinigung durch die Berührung Toter. Zum Ursprung einer altisraelitischen Vorstellung

Postmortale Existenzformen - kosmologische und theologische Aspekte

Gönke Eberhardt: Die Gottesferne der Unterwelt in der JHWH-Religion - Kathrin Liess: »Hast du die Tore der Finsternis gesehen?«(Hi 38,17). Zur Lokalisierung des Totenreiches im Alten Testament - Klaus Bieberstein: Jenseits der Todesschwelle. Die Entstehung der Auferweckungshoffnungen in der alttestamentlich-frühjüdischen Literatur - Bernd Janowski: JHWH und die Toten. Zur Geschichte des Todes im alten Israel

Das Band zwischen den Lebenden und den Toten - zur rituellen Bewältigung des Todes II

Dagmar Kühn: Totengedenken im Alten Testament - Rüdiger Schmitt: Totenversorgung, Totengedenken und Nekromantie: Biblische und archäologische Perspektiven ritueller Kommunikation mit den Toten - Raik Heckl: Zur Rolle der Ahnen in der Grundkonzeption der Hexateuchüberlieferung - Jan Christian Gertz: Das Zerschneiden des Bandes zwischen den Lebenden und Toten in der dtn-dtr Literatur

VI. Tod und Jenseits im antiken Mittelmeerraum - komparatistische Aspekte

Annette Zgoll: Die Toten als Richter über die Lebenden. Einblicke in ein Himmel, Erde und Unterwelt umspannendes Verständnis von Leben im antiken Mesopotamien - Danie/ Schwemer: Tod, Geschick und Schicksalsgöttin: Übergänge zwischen Leben und Tod in babylonischen Abwehrzauber-Ritualen - Joachim Friedrich Quack: Grab und Grabausstattung im späten Ägypten - Joachim Bretschneider: Königsgrab und Herrscherlegitimation in Alt-Syrien im 3. Jahrtausend v.Chr.- Jürgen Zangenberg: Trockene Knochen, himmlische Seligkeit. Todes- und Jenseitsvorstellungen im Judentum der hellenistischfrührömischen Zeit

Angelika Berlejung is Professor for »History and Religion of Israel and its Environment « at the Faculty of Theology of the University of Leipzig, an Extraordinary Professor for Ancient Studies at the University of Stellenbosch/South Africa, a Visiting Full Professor for Biblical Archaeology at Bar Ilan University/Israel, and a Full Member of the Saxon Academy of Sciences. https://orcid.org/0000-0002-4556-9167 
Bernd Janowski Geboren 1943; Studium der Theologie, Ägyptologie und Assyriologie in Tübingen; 1980 Promotion; 1984 Habilitation; nach Professuren in Hamburg (1986-91) und Heidelberg (1991-95) seit 1995 Professor für Theologie des Alten Testaments in Tübingen; seit 1995 Mitglied der Heidelberger Akademie der Wissenschaften; seit 2011 emeritiert.

Jetzt bestellen:

https://mohrsiebeck.com/buch/tod-und-jenseits-im-alten-israel-und-in-seiner-umwelt-9783161511059?no_cache=1 order@mohrsiebeck.com

Telefon: +49(0)7071-923-17

Telefax: +49 (0)7071-51104 